\title{
Water Footprint and the Impact of Food Production Environmental Sustainability
}

\author{
Syreeta Morgan $^{\mathrm{a}}$, Amir Golmohamadi $^{\mathrm{a}, *}$, Hossein Vojoudi $^{\mathrm{b}}$ \\ aagolmohamadi@wcupa.edu \\ a Department of Nutrition, West Chester University of Pennsylvania, USA \\ ${ }^{\mathrm{b}}$ College of Science, University of Tehran, Tehran, Iran
}

\begin{abstract}
Freshwater is a sparse source. It takes a significant amount of water to get food that we eat from the fields to the plates on our dining room tables. What we eat makes up a large number of our water footprints. A water footprint is used to indicate the amount of freshwater that any given process or activity uses. In addition to our diets, issues revolving around water footprint include water depletion and pollution. Water depletion, specifically freshwater depletion refers to the lack of sufficient available fresh water resources to meet water demand. Water pollution occurs when harmful substances such as microorganisms contaminate a source of fresh water such as a lake, stream, or river. The water footprint of food is significantly high and that is why it is important that we reduce food waste to preserve and protect the food available to us.
\end{abstract}

Keywords: Footprint, Sustainability, Fresh water;

\section{Water Footprint}

Widespread water scarcity, water pollution, and depletion of freshwater resources are among the vast environmental challenges of the 21st century in relation to water (Hogeboom, 2020). Measuring water footprints can give us a clear picture of how water is used in today's, society and help us come up with strategies for more sustainable water usage. A water footprint is an indicator that looks at both the direct and indirect water use of an individual, business, community, city, or country. Direct water use is the water we see coming out of the tap. Indirect water use is the water that is used to manufacture the goods that we consume or produce, and the services that we use. The total water footprint of a product breaks down into three components: blue, green, and grey. With that being said, agriculture plays a huge role in our nation's overall water footprint, especially livestock. Nearly one-third of the total water footprint of agriculture in the world is related to the production of animal products. When this later gets translated to the farm to fork, this is responsible for the food waste within our homes and communities (Hoekstra, 2009).

*Corresponding author: Tel: +1 6104362175 


\section{Food Waste}

Getting food from farm to fork takes about $10 \%$ of the total US energy budget, uses $50 \%$ of US land, and devours $80 \%$ of all freshwaters consumed in the US (Gunders, 2021). By 2050, the quantity of food waste is projected to be more than two times the current amount. This request for food could be satisfied only when $70 \%$ of the land area on earth is used for agricultural production, which would force farmers to expand the agricultural land area or to utilize genetic modification techniques to increase output per unit (Huang et al., 2020). Food waste contributes to excess consumption of fresh water and fossil fuels which, along with methane and CO2 emissions from decomposing food, impacts global climate change (Hall, 2009). As stated by Chow, Hall, and Huang, food waste now accounts for more than one-quarter of the total freshwater consumption, urging farmers to use more fresh water for the production of crops (Huang et al., 2020, Hall, 2009). Chow and Hall also mentioned that along with agriculture accounting for about $70 \%$ of our freshwater supply, a quarter of our freshwater use is accounted for by food waste (Hall, 2009). When pondering the concerns involving food waste, we must first begin with examining where in the Food Supply Chain (FSC) that this cycle of food waste begins. It normally begins at the retail/consumer level, but it can start at the farm level also.

\section{Food Production and Consumption}

For us to better comprehend food systems and the food supply chain, we must explain the internal components and boundaries of the system, as well as its connections to an "external" world (Nesheim et al., 2015). Agricultural land plays a significant role in the food supply chain and has seen a great increase in demand for food and commodities in many parts of the country and even worldwide. Crop production is heavily condensed, and farms are becoming heavier, heading to more freshwater use in these specific areas (Nesheim et al., 2015, Spangler et al., 2020). Agricultural sustainability is centered around enhancing environmental quality and the origin of the resources being used. One of the biggest resources in agriculture is freshwater. Understanding this, we must keep freshwater resources before they are used in our everyday agricultural and household activities (Spangler et al., 2020). Once we tackle the problem from the source, we will be able to lessen the issue of food waste altogether. We do this by centering on food consumption. Processed foods require more fresh water to be used versus fruits and vegetables. Fruits and vegetables are foods that Americans tend to waste more than processed foods. Thus, leading to the problem of water being wasted producing fruits and vegetables. Within the next 20 years, scientists and farmers are hoping to see a $5.4 \%$ increase in at-home food consumption and an $8.1 \%$ increase in overall fruit and vegetable consumption in American households (Blisard et al., 2002).

\section{Environment- Freshwater}

Global crop production is causing strain on water and land resources in many places. Some argue that there are not enough freshwater resources to sustain human life. Most of it coming from groundwater and ice and other resources include lakes and rivers (Bunn, 2016). For some crops, water scarcity impacts are contrarywise related to land resource stress, illustrating that water consumption is often at odds with land use. Meaning, the more water we use, the less will be available for land use which includes growing crop for later consumption. Trustworthiness of water and land use-related impacts underlines the significance of appropriate site selection for agricultural activities (Pfister et al., 2011). To add to this problem, increased human activity has further diminished available water supplies by overusing the resources they have and furthering the problem of pollution (Bunn, 2016). Water scarcity decreases crop yields, and people, especially in the 
developing world, may suffer from malnutrition. It is necessary to characterize water consumption according to the environmental influence at the specific site (Pfister et al., 2011).

\section{Agriculture in the US}

Agriculture has drastically changed the earth and its surface over the years. Crop production is heavily concentrated in certain areas, larger farms are getting larger, while the number of smaller operations is decreasing, and crop diversity is declining (Spangler et al., 2020). Major environmental functions and human needs critically depend on water. Freshwater has a multi-functioning purpose with one of them being essential in agriculture, which claimed more than $85 \%$ of human water consumption (D'Odorico et al., 2020). Crops on the other hand require more attention and care due to the heightened water consumption. Crops have very specific water requirements, and these vary depending on local climate circumstances. The production of meat requires between six and twenty times more water than for cereals, for example (Spangler et al., 2020, D'Odorico et al., 2020). Water is an essential component in food production, and water management strategies are needed to provide for worldwide changes in food consumption and dietary arrangements. Water use fluctuates with weather patterns but is also affected by shifts in production technology, supply-chain linkages, and domestic and foreign consumer demand (Stein et al., 2020). With, water is a crucial resource for life on Earth because it is irreplaceable in its role of sustaining the functioning of the environment and societies (D’Odorico et al., 2020).

\section{Environmental and Agricultural Policies}

Over the years, agricultural land use in the United States has seen drastic shifts to support the increasing demand for food and commodities. Crop production is heavily concentrated in certain areas, larger farms are getting larger, while the number of smaller operations is decreasing, and crop diversity is declining. While the federal agricultural policy is increasing, so is its influence as well (Spangler et al., 2020). We need to identify broad policy changes of the U.S. Farm Bills and other bills, rules, and regulations related to agriculture. Agricultural support policies, broadly defined, date to the earliest years of the nation, even to its colonial roots. Public land grants and sales, which continued well into the 20th century, supported agricultural development through encouraging extensive settlement by both large-scale plantations and ranches and smaller-scale independent farmers (Glauber and Effland, 2016).

Water is one of our most precious assets in our everyday lives and we must protect it with everything we have in us. It is vital for human consumption and civilization and supporting ecosystems across the world. Water footprint helps us understand what purpose freshwater resources serve and helps us better understand what is being polluted and what is being preserved. Measuring water footprint and taking all the necessary steps to keep that level as low as possible is extremely important for mankind. This balance is urgently expected because fresh water is crucial to our daily life while the supply of freshwater is limited. As the world population expands, so does the need for fresh water.

Measures to keep water footprint levels low, soon are needed to conserve fresh water supply. As consumers armed with water footprint data, we should be able to make informed choices to purchase goods and services that have a lower water footprint. The fact of the matter is that the impact of water consumption depends on the circumstances. In the future, as a country we need to focus more on policies that protect our fresh water resources. Starting at the source of the problem will only help solve and prevent future problems regarding this issue from occurring. 


\section{Acknowledgements}

The authors wish to thank West Chester University of Pennsylvania's Office of Research and Sponsored Program.

\section{References}

Blisard, N., Lin, B.-H., Cromartie, J., \& Ballenger, N., 2002. America's changing appetite: Food consumption and spending to 2020, Food Review/National Food Review 25, p. 2.

Bunn, S. E., 2016. Grand challenge for the future of freshwater ecosystems, Frontiers in Environmental Science 4, p. 21.

D'Odorico, P., Chiarelli, D. D., Rosa, L., Bini, A., Zilberman, D., \& Rulli, M. C., 2020. The global value of water in agriculture, Proceedings of the National Academy of Sciences 117, p. 21993.

Glauber, J. W., \& Effland, A., 2016. United States agricultural policy: Its evolution and impact, International Food Policy Research Institute 1543.

Gunders, D., 2012. Wasted: How America is losing up to 40 percent of its food from farm to fork to landfill, Natural Resources Defense Council 26, p. 1.

Hall, K. D., Guo, J., Dore, M., \& Chow, C. C., 2009. The progressive increase of food waste in America and its environmental impact, PloS One 4, p. 7940.

Hoekstra, A. Y., 2009. A comprehensive introduction to water footprints. On Line at: Www. Waterfootprint. Org

Hogeboom, R. J., 2020. The Water Footprint Concept and Water's Grand Environmental Challenges, One Earth 2, p. 218.

Huang, C.-H., Liu, S.-M., \& Hsu, N.-Y. (2020). Understanding global food surplus and food waste to tackle economic and environmental sustainability. Sustainability, 12(7), 2892.

Nesheim, M. C., Oria, M., \& Yih, P. T. (2015). Committee on a Framework for Assessing the Health. E. and SE of the FS, Board, F. and N., Resources, B. on A. and N., Medicine, I. of, and Council, NR.

Pfister, S., Bayer, P., Koehler, A., \& Hellweg, S. (2011). Environmental impacts of water use in global crop production: hotspots and trade-offs with land use. Environmental Science \& Technology, 45(13), 5761-5768.

Spangler, K., Burchfield, E. K., \& Schumacher, B. (2020). Past and current dynamics of US agricultural land use and policy. Front. Sustain. Food Syst. 4: 98. Doi: 10.3389/Fsufs.

Stein, S., Sola, F., Yechieli, Y., Shalev, E., Sivan, O., Kasher, R., \& Vallejos, A. (2020). The effects of long-term saline groundwater pumping for desalination on the fresh-saline water interface: Field observations and numerical modeling. Science of The Total Environment, 732, 139249. 